\title{
8. A JUSTIÇA ACIMA DO MOVIMENTO DO CETRO
}

\section{THE JUSTICE UP TO THE SCEPTER MOVEMENT}

Guilherme de Oliveira Feldens ${ }^{1}$

"Terás mais justiça do que querias..."

William Shakespeare

Resumo. O presente artigo tem como objeto analisar a necessária relação entre Direito e justiça na obra $O$ mercador de Veneza de Shakespeare. A partir do julgamento do judeu Shylock, o texto analisa os principais discursos proferidos pelos personagens em tribunal, objetivando visualizar o fundamento da moral e da justiça presente na obra.

Palavras-chave: Direito. Moral. Justiça.

Abstract. This article aims to analyzes the relation between law and justice in The Merchant of Venice by Shakespeare. From the judgment of the Jew Shylock, the text analyzes the major speeches of characters in court, aiming to visualize the foundation of morality and justice present in the work.

Keywords: Law. Moral. Justice.

\section{Introdução.}

A obra O mercador de Veneza, além de apresentar como poucas a complexidade da natureza humana, narra uma série de fatos capazes de originar um amplo debate acerca das relações entre Direito e Justiça. Apesar do contrato firmado por Shylock e Bassânio, tendo Antônio como fiador, e a cláusula referente a seu descumprimento serem os pontos bastante destacados nas análises jurídicas feitas sobre a obra, há outros inúmeros elementos capazes de gerar reflexão em relação a questionamentos fundamentais da teoria geral do Direito.

\footnotetext{
${ }^{1}$ Doutorando em Filosofia do Direito pela Unisinos, Mestre em Direito, Professor de Ciência Política e Teoria Gerald o Estado do Cesuca, Coordenador Adjunto do Curso de Direito do Cesuca, Professor de Ciência Política e Teoria Geral do Estado. E-mail: b2ico@hotmail.com
} 
Nessa perspectiva, o presente texto pretende analisar o discurso de Pórcia no tribunal, no qual a personagem defende a compaixão como um sentimento necessário aos homens, verificando a relação de tal discurso com o fundamento da moral determinado por Schopenhauer e seu contraste com os juízos morais normativos característicos do pensamento jurídico moderno.

\section{Quando a misericórdia tempera a justiça em $O$ mercador de Veneza}

A obra o Mercador de Veneza caracteriza a imposição de um novo paradigma para seu tempo. Shakespeare, antecipando a filosofia moderna, centra todo o desenvolver dessa história na ideia de vontade, concretizada em vários contratos que conduzem toda a trama. ${ }^{2}$ Entre esses contratos, ganhou destaque, tornando-se ponto batido nas análises jurídicas, a celebração entre Shylock e Bassânio, no qual o primeiro cede a quantia de três mil ducados, tendo Antônio como fiador. Shylock estabelece também como penalidade ao não pagamento do valor emprestado na data e local estipulados, a "retirada" de uma libra da carne de Antônio, a qual poderia ser escolhida e cortada a critério do credor ${ }^{3}$.

No desenvolver da trama, Antônio, cuja fortuna estava empenhada em expedições marítimas, recebe a notícia de que todas as suas embarcações foram perdidas em naufrágios, o que o impede de satisfazer a dívida assumida. Vencido o prazo, Shylock, movido pelo ódio por Antônio, requer, então, a execução da penalidade estipulada pelo descumprimento do contrato. Inicia-se, então, o processo judicial para execução da referida cláusula penal, no qual Pórcia, esposa de Bassânio, se faz passar por um jovem jurista, tentando impedir a execução da cláusula penal. Assim sendo, o julgamento caracteriza "dois lados" opostos: Shylock, clamando por justiça, invoca a lei de Veneza, exigindo que ela seja estritamente observada e, portanto, que seu direito à libra de carne seja garantido em nome da ordem e da preservação do próprio ordenamento; e Pórcia (disfarçada de Baltazar) se esforçando para desvincular a justiça com o estrito cumprimento da lei.

\footnotetext{
${ }^{2}$ Entre esses outros contratos, pode-se citar a "charada" imposta pelo falecido pai de Pórcia como condição necessária para que Bassânio pudesse ter a moça; além da questão dos anéis imposta pelas mulheres em relação aos homens.

${ }^{3}$ Novamente essa questão reforça o aspecto da autonomia da vontade em Shakespeare, como é possível verificar no discurso de Shylock: "O senhor vai me perguntar porque prefiro ter um peso em carne de carcaça em vez de receber três mil ducados. A isso, eu me dou o direito de não responder...digamos que é a minha vontade. Está respondida a pergunta? [...] Assim é que não tenho nenhuma boa razão para apresentar, e nem quero; a não ser a raiva alojada em mim e o firme ódio que sinto por Antônio. A esta raiva e a este ódio dou seguimento, com um processo na justiça contra ele, que a mim não traz ganho algum” (Shakespeare, 1995, p.
} 98). 
Em busca de seu objetivo, Pórcia suplica por compaixão:

A misericórdia é uma virtude que não se pode fazer passar à força por uma peneira, mas pinga como a chuva mansa cai dos céus na terra. É duplamente abençoada: abençoa quem tem compaixão para dar e quem recebe. Poderosa nos poderosos, harmoniza-se com o monarca ao trono melhor que a coroa [...] Ela tem seu trono no coração dos reis [...] é um poder mundano que se mostra divino...quando a misericórdia vem temperar a justiça. Portanto, judeu, embora o cumprimento da justiça seja a tua argumentação, considere o seguinte: no cumprimento da justiça, nenhum de nós vai encontrar a salvação.

Assim, Pórcia tenta mitigar a argumentação de Shylock em "prol da justiça" apresentando um fundamento moral. Nesse momento, Shakespeare evidencia as várias estratégias de Pórcia em tentar desmotiva o judeu de seu objetivo, apelando tanto à uma moral normativa (fundada em obrigações) como em um discurso que coloca a compaixão como fundamento último da obrigação moral. Essa questão, de certa forma, segue em debate nas analises filosóficas relativas à moral.

\section{O Fundamento da Moral em Schopenhauer}

O discurso de Pórcia em defesa de Antônio, ao colocar a compaixão acima da justiça, aproxima-se da tese sobre o fundamento moral proposto por Schopenhauer. Em sua obra Sobre o fundamento da moral, ao expor a motivação moral, Schopenhauer a demonstrou como fato e que só a partir dela podem surgir a "justiça desinteressada" e a "caridade genuína". Essa exposição não é sonhada ou apanhada no ar, mas algo bem real, um fenômeno diário de "participação imediata, independente de qualquer outro motivo, no sofrimento de um outro" (Schopenhauer, 1995, p. 129). Segundo o autor, para fundar a ética isto é suficiente, já que ela tem de se apoiar sobre algo existente, efetivo, "dado ou no mundo exterior ou na consciência, se não se quiser acaso admitir arbitrariamente, como alguns de meus predecessores, um princípio abstrato e dele derivar as prescrições éticas" (Schopenhauer, 1995, p. 195).

Schopenhauer, da mesma forma que Pórcia, afirma que, analisando a compaixão apenas de um ponto de vista empírico, todos se convenceriam de que para aliviar os sofrimentos aos quais a vida está exposta e para combater o egoísmo que preenche todo ser, "a natureza nada poderia ter produzido de mais eficaz do que plantar no coração humano aquele gérmen graças ao qual o sofrimento de um é sentido conjuntamente pelo outro" (Schopenhauer, 1995, p. 174). É melhor para todos a assistência mútua assim considerada do que um mandamento geral e abstrato do dever, pois esse é 
incompreensível para o homem rude ao qual apenas o caso concreto significa alguma coisa (Schopenhauer, 1995, p. 175).

Porém, ao final da obra, Schopenhauer apresenta a necessidade de uma explicação metafísica, referindo-se a sua obra $O$ mundo como vontade e representação. O autor, então, pergunta se relação entre o próprio eu e o alheio, que fundamenta as ações do caráter bom, se apóiam em um engano. Assim, remetendo as considerações metafísicas, Schopenhauer afirma que a multiplicidade e diferença dos seres repousa apenas diante do espaço e do tempo, sendo estes estranhos a coisa-em-si. A multiplicidade pertence "somente ao mero fenômeno e é uma e a mesma essência que se apresenta em todos os viventes" (Schopenhauer, 1995, p. 206), sendo a compaixão a base metafísica da ética, pois suprime a diferença entre o eu e o não-eu . A compaixão não é uma exigência moral, mas é o elemento de apreensão de que todas as coisas fora de mim são também vontade. Através dela o indivíduo deixa de estar submetido ao princípio de individuação.

Portanto, em Schopenhauer, não temos uma moral de obrigações. A moral não está no que cada indivíduo representa ou faz em vista dos outros, mas naquilo que é em si mesmo. Ela reflete o caráter, e precede a representação. Esse último é o campo no qual se situa a política, portanto, não há um objetivo em Schopenhauer de procurar uma obrigação moral universal da compaixão, já que não há prescrições em seu texto, mas explicação do fenômeno ético.

Schopenhauer estabelece estas argumentações da ética no Livro IV de O mundo como vontade e representação. Através de uma interpretação do significado ético da conduta, ele afirma que a compaixão não é uma exigência moral, mas é o nome da experiência (conhecimento intuitivo) de que todas as coisas fora de mim são também vontade e sofrem dores como eu sofro. Através do sentimento da compaixão o indivíduo deixa de estar submetido ao princípio de individuação. Para ele, as qualidades morais dos indivíduos resultam de um caráter inalterável, e a compaixão não pode ser desenvolvida pela educação moral. Ela é espontânea, não estando sujeita a regras de nenhum tipo. A virtude desinteressada não nasce do conhecimento abstrato, pois sua origem está no conhecimento imediato e intuitivo que não pode ser ensinado ou regulado, "mas deve sempre revelar-se de per si; e que para exprimir-se de modo adequado recorre não a discursos, mas aos fatos, à conduta, a toda a maneira de viver" (Schopenhauer, 2005, p.275).

Esta consideração fica clara quando se compreende o homem como manifestação da Vontade. Esta, conforme Schopenhauer, não é representação, ela é a coisa-em-si, 
não havendo, então, razão ou princípio que a determine. A Vontade é um impulso presente em todos os seres vivos. Ela nunca muda por uma ação exterior ou instrução (Schopenhauer, 2005, p.300). Portanto, uma ética normativa não seria eficaz. A ética em Schopenhauer, conforme o demonstrado é descritiva, pois, a virtude não provém do conhecimento abstrato, mas do conhecimento intuitivo, o qual não pode ser comunicado, surgindo no íntimo do indivíduo, nos atos, na conduta.

A análise de Schopenhauer não tem como objetivo principal questões de juízos morais, nem a relação entre os planos individual e coletivo, característica das reflexões modernas. Dentro da abordagem total de sua obra, a compaixão não é base para um princípio de reciprocidade, mas da unidade. Na compaixão a vontade é negada, pois o homem de bom caráter percebe o sofrimento do outrem como se fosse seu, agindo de forma desinteressada. Reconhece, portanto, que a sua essência existe em tudo que vive, enquanto que o homem de mau caráter é condicionado pelo egoísmo, envolto pelo princípio de individuação, nada enxerga além do "Véu de Maia". Esta atitude desinteressada manifestada na compaixão leva o indivíduo a caminho da redenção, a renúncia da Vontade. Assim, a ética não está marcada pela relação com os outros, pois a salvação resulta de um ato do indivíduo, e diz relação à unidade.

\section{A Crítica Moderna ao Fundamento Moral de Schopenhauer.}

No texto Lições sobre ética, Tugendhat expõe o que poderia significar fundamentar uma moral moderna, propondo uma fundamentação que não seria mais de tipo tradicional ${ }^{4}$. A fundamentação dos juízos morais é para este autor uma questão fundamental, sendo intrínseca à própria compreensão da moral. Tugendhat, ao ter os juízos morais como o elemento central do conceito de moral, tem na determinação normativa o fim da moral, visando tira-la de uma fundamentação transcendente.

Segundo ele, uma moral se define como "o conjunto de juízos morais de que alguém ou um grupo dispõe"(Tugendhat, 1996, p. 49). Tugendhat afirma que não há como fundamentar a moral na razão de forma absoluta, pois não existe um ter de absoluto, o ter de é sempre relativo a um querer, a um ato de vontade. Assim, ele

\footnotetext{
${ }^{4}$ Segundo Tugendhat, "temos que sustentar que o potencial de fundamentação de uma moral tradicionalista é limitado através do estabelecimento, pela fé ou pelo dogma, de um conceito de bem, e que está relacionado ao fato de a idéia de bem - de uma preferência objetiva - ser delimitada de tal maneira que propriamente entra em choque com o seu próprio sentido e com o sentido dos juízos morais. $\mathrm{O}$ fato de que apesar disso também hoje ainda muitos sejam da opinião de que uma moral somente pode ser fundamentada pela religião pode provir da circunstância de muitos de nós terem sido socializados desta maneira, e sobretudo da circunstância de até hoje não existir uma fundamentação não-religiosa da moral que tenha encontrado um reconhecimento universal" (1996, p. 72).
} 
argumenta a favor da maior plausibilidade do seu conceito moral, alegando que a sustentação de um conceito qualquer não pode pretender mais do que a plausibilidade.

Tugendhat afirma que a moral é relativa a sanções internas vinculadas a sentimentos que expressam juízos morais (culpa e vergonha), estando presentes, na justificação dos juízos morais, elementos racionais e emocionais. Através dessa idéia de sanção interna, seria possível uma ética do dever independente de sanções externas (moral religiosa), na qual a moral faz parte da compreensão do homem como membro de uma comunidade ${ }^{5}$. A pessoa moral é definida pela sua condição de indivíduo social, e não de simples situação de indivíduo isolado. Em Tugendhat, os sentimentos morais têm a função, do ponto de vista subjetivo dos membros cooperativos de uma comunidade moral, de assegurar a observância das normas. Portanto, a base do comportamento moral não é um conjunto de regras de ação, mas um sistema de exigências mútuas fundado em um conceito de bom, compartilhado por todos na comunidade moral ('autonomia coletiva") 6 .

Assim, em sua "Nona Lição", Tugendhat critica a fundamentação moral de Schopenhauer. Apesar de ambos os autores recusarem uma fundamentação tradicional da moral e de criticarem o fundamento kantiano da moral, suas teorias apresentam a "intenção" de interpretar e "corrigir" Kant. Por meio da crítica ao fundamento exclusivamente racional da moral kantiana, os dois autores colocam os sentimentos na explicação do fundamento da moral. Porém, criam perspectivas diferentes para a fundamentação de suas teses.

Dentro de tal realidade, Tugendhat na citada lição parte da posição de que o conceito de Schopenhauer não apenas não é plausível, bem como de forma alguma é um conceito moral, alegando apenas que sua insistência com a compaixão é "algo importante" (Tugendhat, 1996, p. 178). Tugendhat afirma que, na crítica a Kant, o filósofo dinamarquês além de condenar a idéia de uma pura razão prática e o discurso de um dever absoluto, "ele também condena o imperativo categórico quanto ao conteúdo,

\footnotetext{
5 "Se um indíviduo fere um tal sistema normativo ao qual pertence, ele fere suas próprias regras, que são igualmente as regras de todos. Ele fere a todos os outros em sua capacidade de portadores dessa regra. E podemos dizer que a reação dos outros ao serem feridos dessa maneira é o que é terrível para aquele que feriu a ordem. Mas o é somente se ele se entende como membro dessa sociedade moral." (26)

${ }^{6}$ Tugendhat afirma que "a única maneira de definir uma ordem normativa justa é pensar que os indivíduos se impuseram eles mesmo essa ordem. Uma ordem justa é uma ordem autônoma. Porém, essa autonomia não consiste, como aparece na ética de Kant, em que cada indivíduo imponha a si a ordem e o mesmo ocorra com todos os outros, mas em que os indivíduos se sobreponham e se subordinem reciprocamente a essa ordem. Isso pode ser chamado de autonomia coletiva (distingue-se da autonomia de uma coletividade por ser a autonomia dos indivíduos, mas dos indivíduos na coletividade).Cada um é ao mesmo tempo origem da norma e objeto da norma. (26)
} 
Revista Diálogos do Direito

porque este residiria pretensamente sobre o egoísmo" (Tugendhat, 1996, p. 179), colocando como fundamento exclusivo da moral a compaixão.

Para Tugendhat, tal fundamento apresenta muitas dificuldades. A principal delas é que ao se desvincular a normas particulares e pensar em uma situação complexa de ação, com diversas normas simples e direitos de várias pessoas envolvidas, o fundamento de Schopenhauer não oferece critério de ponderação ${ }^{7}$. Essa dificuldade demonstraria que o seu princípio é completamente inútil para uma ética política, na qual sempre se deve ponderar entre os interesses de muitos e entre direitos (Tugendhat, 1996, p. 181).

Segundo o autor, a ética schopenhauriana restringe-se apenas a constatar que ao lado das ações egoístas também existem as altruístas, movidas por compaixão. Portanto, isso não poderia ser chamado de moral se a compreendermos como um sistema de normas (contratualismo) e se para a moral é fundamental um conceito de bom ${ }^{8}$. A compaixão seria apenas um sentimento "mais ou menos forte, que existe naturalmente e que como tal está moralmente desnorteado" (Tugendhat, 1996, p. 185), não permitindo a necessária universalização. Ela, então, não serviria como critério quando estivessem envolvidos direitos morais que não se fundamentam no sofrimento e quando estivessem, mesmo no seu próprio domínio, envolvidas várias pessoas. Concluindo tal afirmação, Tugendhat alega que é possível "que por compaixão procedamos moralmente errados: se nos deixamos conduzir exclusivamente pelo sofrimento do outro, podemos ir contra os seus outros direitos e podemos sobretudo ir contra os direitos dos outros" (Tugendhat, 1996, p. 185).

Porém, Tugendhat, ao criticar o fundamento da moral de Schopenhauer desconsidera a dimensão metafísica do autor, apresentada na obra O mundo como vontade e representação. Desta forma, Tugendhat faz um julgamento incompleto da concepção de moral, pois desconsidera a "explicação metafísica do fenômeno ético originário". As análises de Tugendhat referem-se apenas à questão proposta pela

\footnotetext{
${ }^{7}$ Segundo Tugendhat, o imperativo categórico fornece o critério para que se decida de tal maneira como qualquer um haveria de querer que se agisse numa situação desse tipo. É neste contexto que se mostram as forças do princípio kantiano, que por conseguinte, de nenhuma maneira - como entendia Schopenhauer - se deixa reduzir a um formalismo vazio, que resultaria do princípio da razão. O princípio de Schopenhauer, neminem laede, ao contrário, absolutamente não oferece um critério de ponderação. Nesta relação, o seu alcance não é maior do que a $2^{\circ}$ fórmula de Kant" (Tugendhat, 1996, p.181).

8 "Para Schopenhauer desaparece o conceito de bom; o sentimento, para o qual ele apela, não é nem um sentimento pelo elemento moral, nem um sentimento moral pelos seres humanos. É um sentimento que, independente da moral, é empiricamente pré-dado e determina, por sua vez, o que deve ser visto como moral [...] A verdadeira dificuldade deste princípio é que, como já disse na quarta lição, a compaixão, enquanto sentimento natural, somente existe mais ou menos [...] Pode um tal sentimento, naturalmente pré-dado e existente em graus diversos, ser fundamento para uma obrigação?" (1996, p. 183)
} 
Sociedade Real Dinamarquesa de Ciências de Copenhague, na qual, a partir da crítica à moral kantiana, Schopenhauer rejeita toda moral de dever e afirma a compaixão como base efetiva de toda moral. Para Schopenhauer, a questão proposta limita-se apenas ao caminho empírico ${ }^{9}$, mas o conhecimento do mundo não se encontra restrito a representação, tendo algo que a precede. Este é um aspecto fundamental na filosofia do autor esquecido ou ignorado por Tugendhat.

A crítica de Tugendhat, segundo a qual a moral schopenhauriana não poderia ser chamada de moral se a compreendermos como um sistema de normas fica afastada, já que não há um objetivo em Schopenhauer de procurar uma obrigação moral universal da compaixão. Não há prescrições em seu texto, mas explicação do fenômeno ético. Percebe-se, que Tugendhat critica a concepção de moral de Schopenhauer de uma perspectiva normativa, justamente objeto da crítica do primeiro.

\section{A caridade e o Direito}

Além dessa marca, o discurso de Pórcia serve como uma perspectiva crítica ao mundo jurídico atual, pois reforça o conceito de "próximo". Sobra visão social e realismo no texto de Shakeaspeare, já que os pressupostos sociais das relações entre os homens na sociedade moderna acabaram por tornar os próprios indivíduos objetos. O discurso de Pórcia não fica indiferente contra a coisificação, agarrando-se necessariamente no conceito de próximo, firmando uma ideia de justiça inseparável de uma compreensão da sociedade, além de uma mera doutrina interior de igualdade.

Conforme o exposto, verifica-se o desenvolvimento do paradigma da alteridade humana, deslocando a marca da existência autossuficiente do "Eu", típica da modernidade, para o reconhecimento da importância do "próximo". Dessa forma, o a defesa de Pórcia parece ter seu ponto de partida no reconhecimento da alteridade do outro, indo além das perspectivas da subjetividade Moderna. Verifica-se, portanto, a presença de um conceito de igualdade verdadeiro, pois afasta a suposição de que cada

\footnotetext{
9 "Talvez se queira objetar-me que a ética nada tem a ver com o fato de como os homens efetivamente agem, mas que ela é a ciência de como devem agir. Mas é justo esse princípio que eu nego, depois que provei suficientemente, na parte crítica dessa dissertação, que o conceito do dever, a forma imperativa da ética só são válidos na moral teológica e que perdem todo o sentido e significação fora dela. Proponho, em contrapartida, como finalidade para a ética, a de esclarecer, explicar e reconduzir à sua razão última os modos muito diferentes de agir dos homens no aspecto moral. Por isto, resta apenas para a descoberta do fundamento da ética o caminho empírico, a saber, o de investigar se há em geral ações às quais temos de atribuir autêntico valor moral - que seriam as ações de justiça espontânea, pura caridade e generosidade efetiva" (Schopenhauer, 1995, p. 113).
} 
indivíduo depende apenas de si mesmo para se manter e de que a presença do próximo (ou do "outro") seja completamente dispensável.

Essas ideias trazem uma forte vinculação moral à perspectiva jurídica, pois o discurso de Shakespeare mostra acima de tudo que o Direito precisa de uma justificação. Portanto, desponta o problema da legitimação da autoridade que a lei supõe. Esse problema propõe a discussão sobre a legitimidade do uso da violência ao serviço da justiça, ou de fins considerados suficientemente justos para legitimar determinadas previsões legais.

\section{Conclusão}

O texto de Shakespeare (exteriorizado na personagem Pórcia) apresenta uma forte vinculação com o discurso ético e jurídico de Arthur Schopenhauer. Em ambos, visualiza-se a necessidade de buscar nas relações humanas o centro referencial fundamentação da moral e do Direito. Para o filósofo, enquanto que a Moral, através da análise da conduta humana, se preocupa com a prática da (in) justiça, o Direito tem por centro de referência o sofrer injustiça.

Dessa forma, cabe a lei assegurar os direitos de todos, protegendo os cidadãos do sofrimento da injustiça causada pela ação egoísta. A prática da justiça e o não sofrer injustiça se apresentam fortemente relacionadas no fundamento moral apresentado por Schopenhauer. Esse aspecto é de vital importância para as discussões jurídicas modernas, já que os principais filósofos do Direito parecem ignorar as construções teóricas de Schopenhauer, abandonando o discurso de Pórcia, segundo o qual no cumprimento da justiça (lei), nenhum de nós vai encontrar a salvação.

\section{REFERÊNCIAS BIBLIOGRÁFICAS}

SCHOPENHAUER, Arthur. Sobre o fundamento da moral. São Paulo: Martins Fontes, 1995.

O mundo como vontade e como representação. São Paulo: Edunesp, 2005.

SHAKESPEARE, William. O Mercador de Veneza. Trad. F. Carlos de Almeida Cunha Medeiros e Oscar Mendes. São Paulo: Martin Claret, 2007.

TUGENDHAT, Ernst. Lições sobre ética. Petrópolis, RJ: Vozes, 1996.

(Artigo recebido em 06/11/2013 e aceito para publicação em 12.12.2013) 